\title{
Das volle Leben
}

\section{Erhard Taverna}

Ein Endokrinologe, ein Psychiater, eine ORL-Ärztin und ein Gynäkologe ziehen Bilanz. Jan A. Fischer, mit einem goldenen Löffel geboren, Asienreisender, erfolgreicher Forscher und Kunstsammler, der von sich sagen kann: "Das reine Glück und meine Fortuna sind allgegenwärtig.» Niklaus Gaschen, der unaufhörlich um seine Selbstfindung kreist. Béatrice Deslarzes, Medizinerin, Jazzsängerin, Gemeinderätin und Mäzenin. Pierre Schaefer, Gynäkologe am Unispital Genf, Zeichner, Fotograf und Mitmäzen der mit seiner Ehefrau gegründeten Fondation Bea pour Jeunes Artistes.

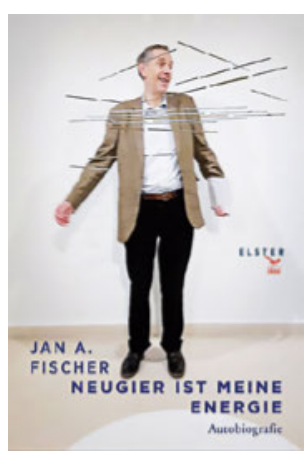

Jan A. Fischer

Neugier ist meine Energie

\section{Autobiografie}

Zürich: Elster Verlag; 2018.

ISBN 979-3-906903-02-6

192 Seiten. 34 CHF.

Zum 80. Geburtstag hat sich Jean A. Fischer eine Autobiografie gegönnt. Ansprechend gestaltet und schön bebildert, wie alle seine Bücher zuvor. Eine spannend erzählte Familiengeschichte und eindrückliche Reportage über die verschiedenen Stationen eines langen Lebens. Geboren als einziges Kind einer Industriellenfamilie in Schaffhausen, beendete er sein Medizinstudium, wie seine Mutter, in Zürich. Seinem Jahreskurs in Cambridge folgte eine abenteuerliche Reise nach Iran und Afghanistan. In Anlehnung an die Mayo-Klinik begann seine Forschungsarbeit an der Orthopädischen Universitätsklinik Balgrist. Fischers beruflicher Werdegang ist ein Stück Geschichte der neueren Biologie, die er bis zu seiner Eremitierung mitgestaltete. Kunst und Reisen prägen die letzten Jahrzehnte. Seine eigene Sammlung mit Kunstobjekten aus aller Welt, mit vielen intensiven Begegnungen sowohl mit Künstlern wie mit Kunsthändlern. Verbindende Freundschaften, die im Haus und im Garten ihre Spuren hinterlassen haben. Der Jubilar macht uns zu Partnern seines Glücks. Dafür sei ihm gedankt.

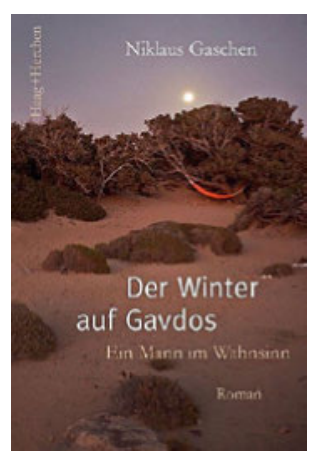

Niklaus Gaschen Der Winter auf Gavdos

Hanau: Haag + Herchen; 2018. ISBN 978-3-89846-806-0 256 Seiten. 28.90 CHF.

Der alt gewordene Psychiater und Schriftsteller Nepomuk Gupf findet sich im freiwilligen Exil auf der kleinen ägäischen Insel Gavdos. Mit dabei, wie in allen Romanen, der unentbehrliche Camper. Friedrich Nietzsche und Friedrich Hölderlin sind die geistigen Weggefährten des einsamen Alter Ego, dessen Gedanken immer wieder um die erlebte Nichtexistenz in der Öffentlichkeit kreisen. Dem bukolischen Landleben mit einer griechischen Familie und einer zaghaften Liebesgeschichte folgt der jähe Wechsel in die Berner Wohnung. Es läutet an der Wohnungstür und Gupf soll zurück in die Psychiatrie, wo er schon einmal ausgerissen ist. Ein grauenhaftes Flashback, ein déjà- $v u$-Erlebnis von wüstem Alptraumcharakter. Nur die Frau des Polizisten interessiert sich für seine bewegende Geschichte und nimmt sich, als erste Leserin, regelmässige Besuche und Gespräche in der Klinik vor.

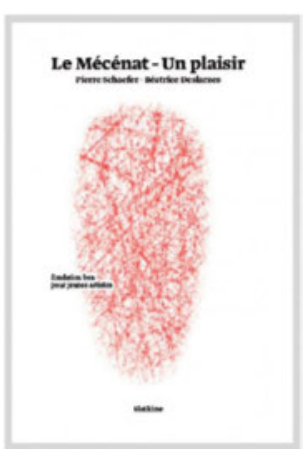

Pierre Schaefer, Béatrice Deslarzes Le Mécénat - Un plaisir

Fondation Bea pour Jeunes Artistes Genève: Editions Slatkine; 2018. ISBN 978-2-8321-0869-7 144 Seiten. 24.40 CHF.

2003 hat das Ehepaar Schaefer und Déslarzes die Fondation Bea pour Jeunes Artistes, mit Domizil in Morgins, Wallis, gegründet. Sie hat zum Ziel, junge Künstler, die noch am Beginn ihrer Karriere stehen, mit Geld, Preisen und Projekten zu fördern. Die Stiftung ist vor allem in der Romandie und im Wallis aktiv und möchte beispielhaft weitere Mäzene und Sponsoren für diese anspruchsvolle Aufgabe animieren, vor allem in einer Zeit, in der der Staat seine Beiträge immer weiter kürzt. Eine lange Geschichte mit Höhen und Tiefen, die aus der Westschweizer Kunstszene nicht mehr wegzudenken ist. Ein engagiertes Leben, das zahlreichen kreativen Menschen den Weg zum Erfolg ermöglichte. Das mit vielen Fotografien dokumentierte Buch vermittelt einen Eindruck in das aufopfernde Schaffen eines Mediziner-Künstlerpaars, das unermüdlich vorlebt, was es bedeutet, mit Herzblut ein Mäzen zu sein. 